\title{
Within-season Stability of Strawberry Soluble Solids Content
}

\author{
Tomas N. Hasing, Luis F. Osorio, and Vance M. Whitaker ${ }^{1}$ \\ Gulf Coast Research and Education Center, University of Florida, 14625 CR 672, \\ Wimauma, FL 33598
}

\begin{abstract}
AdDITIONAL INDEX words. Brix, dynamic stability, Fragaria $\times$ ananassa, fruit quality, static stability
Abstract. Previous studies have recognized considerable variation in the soluble solids content (SSC) of strawberries (Fragaria $\times$ ananassa) during Florida's fruiting season. Cultivars with stable fruit SSC over time would be valued in the commercial industry as a result of their more uniform quality. The within-season stability of 410 genotypes from the strawberry breeding program of the University of Florida was estimated using data from clonally replicated firstyear seedlings and advanced selections evaluated at two locations over two consecutive seasons. Stability was measured using a linear regression approach. For each genotype, the SSC measured at different harvest dates was regressed on the mean SSC of an independent set of genotypes at each harvest date. Genotypes with steep slopes are sensitive to small environmental and physiological changes and are considered unstable compared with genotypes with slopes close to zero. Approximately $90 \%$ of individual genotype slopes were not different from the population slope value and were classified in the average stability group, whereas the remaining $10 \%$ were equally distributed between the unstable and stable groups. Although a preliminary genetic analysis indicated that SSC stability may have low narrow-sense heritability $\left(h^{2}=0.06 \pm 0.05\right)$, a group of genotypes exhibited stability across multiple environments. Soluble solids content stability and mean soluble solids were independent, and genotypes with both stable and high levels of SSC were observed.
\end{abstract}

Soluble solids content is an important element of strawberry fruit quality. Approximately $80 \%$ to $90 \%$ of the SSC consists of sugars (Perkins-Veazie, 1995), and high levels have frequently been associated with favorable sensory ratings in taste panel evaluations (Jouquand et al., 2008; Wozniak et al., 1997). Either SSC alone or its value relative to the percentage of titratable acidity in the fruit correlates positively with the level of sweetness perceived by panelists (Sims et al., 1997).

Studies examining the inheritance of SSC in strawberries (Shaw 1988, 1990; Shaw et al., 1987) have estimated varying levels of additive and dominance control and demonstrated some selection response for this trait. Shaw (1988) detected substantial differences in SSC across harvests and also found significant genotype $\times$ harvest interactions that accounted for $30 \%$ of the phenotypic variance. Jouquand et al. (2008) and Whitaker et al. (2011) reported similar interactions during Florida's growing season, and they noted that the fruit SSC for some genotypes was more variable than for others.

Differences in strawberry SSC across harvest dates have been previously associated with changes in a number of plant physiological states and environmental conditions. For example, sugar uptake rates have been shown to be higher in primary fruit (Forney and Breen, 1985), which predominate at the beginning of harvest cycles (MacKenzie and Chandler, 2009). In addition, Olsen et al. (1985) detected changes in the source-sink ratio throughout the fruiting period that may also affect SSC. Recently, MacKenzie et al. (2011) implicated increasing temperature as the major cause of declining SSC at the end of the season in Florida. The SSC decline appeared to be independent of changes in yield in this study. Regardless of the underlying causes for SSC variation in strawberry fruit, cultivars that maintain stable SSC throughout the season would

Received for publication 30 Nov. 2012. Accepted for publication 13 Feb. 2013. ${ }^{1}$ Corresponding author. E-mail: vwhitaker@ufl.edu. be highly desirable as a result of their more uniform eating quality. The typical fruiting season in west-central Florida extends from late November to late March and is characterized by widely varying environmental conditions, making Florida an ideal location to examine SSC stability over time.

A number of procedures have been proposed to analyze the stability of genotypes across different environments. Extensive reviews of these methods have been prepared by Becker and Leon (1988) and Freeman (1973). Most were developed to evaluate agronomic crops that are harvested only once in a season and are assessed for stability (usually yield stability) across multiple environments (unique combinations of location and year). However, by modeling correlations for observations arising from the same plant, the regression approach introduced by Finlay and Wilkinson (1963) can be adapted to withinseason stability analyses by considering each harvest as a separate "environment."

In the regression approach, the performance of individual genotypes is linearly regressed against the population mean for each environment or against the mean of an independent set of genotypes (Freeman and Perkins, 1971) in each environment. These environmental means reflect the combined effects of physiological and environmental conditions that were common to all genotypes in the environments and estimate how favorable conditions were for the trait of interest. Unstable genotypes are sensitive to small changes in field conditions and are associated with steeper slopes. Genotypes with slope estimates close to zero are considered stable according to the static concept in that they do not react as much to changes in field conditions. Genotypes with slopes close to 1.0 (or close to the population's slope) have average stability across the season, but they may also be considered stable according to the dynamic concept of stability (Becker and Leon, 1988). The regression approach to stability has been successfully applied in a number of crops and traits, including such diverse examples as yield in 
triticale [ $\times$ Triticosecale (Goyal et al., 2011)], fruit size in bell pepper [Capsicum annuum (Stoffella et al., 1995)], ripening date of blueberry [Vaccinium sp. (Gupton et al., 1996)], and isoflavone content (Murphy et al., 2009), phosphorus concentration (Maupin et al., 2011), and oleic acid content (Lee et al., 2012) in soybean (Glycine max). A retrospective study in processing tomato (Solanum lycopersicum) used regression to examine soluble solids stability across environments (Ashburner et al., 2003). They determined that soluble solids stability was a better predictor of cultivar adoption than mean soluble solids across the environments.

The objective of this study was to examine the within-season stability of SSC for a representative subset of genotypes in the strawberry breeding program of the University of Florida. By 1) examining the variation for SSC stability in this set of germplasm; 2) exploring the relationship between SSC stability and other traits such as mean SSC and yield; and 3) obtaining a preliminary estimate of the heritability of SSC stability, the potential for measuring and making improvements in this trait and selecting stable individuals can be more accurately assessed. To our knowledge, this study is the first application of the regression approach to examine stability across harvest dates within environments.

\section{Materials and Methods}

Plant Material and data collection. SSC data were gathered during two consecutive strawberry growing seasons in 2010-11 and 2011-12. In each season, the evaluations were conducted at two locations: the Gulf Coast Research and Education Center in Balm, FL (lat. $27^{\circ} 45^{\prime} 37.98^{\prime \prime} \mathrm{N}$, long. $82^{\circ} 13^{\prime} 32.49^{\prime \prime} \mathrm{W}$ ) and the test plots of the Florida Strawberry Growers Association in Dover, FL (lat. $28^{\circ} 0^{\prime} 55.55^{\prime \prime} \mathrm{N}$, long. 82 $14^{\prime} 5.24^{\prime \prime} \mathrm{W}$ ).

The population evaluated during the 2010-11 season consisted of unselected seedlings from 26 biparental crosses organized in two sets. The first set was composed of 371 seedlings from 19 crosses following a five $\times$ four factorial mating design (one cross missing). The second set consisted of 134 seedlings from seven biparental crosses that were made among 10 different parents. This set constituted a random sample of the crosses already generated in the breeding program for evaluation during the 2010-11 season. Fourteen additional control genotypes, including cultivars and advanced selections, were also included. Crosses from both sets were representative of the strawberry breeding program at the University of Florida in the sense that they were part of the main genetic pool that is evaluated to select outstanding individuals.

The population evaluated during the 2011-12 season consisted of 200 advanced selections and eight cultivars. The selections accounted for $78 \%$ of the breeding program's collection of elite genotypes and originated from 92 crosses between 86 parents. Fifty of these selections were evaluated for SSC as unselected seedlings in 2010-11 and, therefore, were replicated across the two seasons.

Seedlings and selections were asexually propagated at the breeding program's summer nursery site in Monte Vista, CO (lat. $37^{\circ} 40^{\prime} 46.10^{\prime \prime} \mathrm{N}$, long. $106^{\circ} 8^{\prime} 10.83^{\prime \prime} \mathrm{W}$ ) where they were clonally propagated through runners during the summers of 2010 and 2011. Multiple bare-root daughter plants (runners) from each genotype were dug and shipped to Florida $\approx 10 \mathrm{~d}$ before planting. Four plants per seedling were established during the first season, two at the Balm location on 11 Oct. 2010 and two at Dover on 14 Oct. 2010. During the next season, eight daughter plants from each selection were established at the same locations, four at Balm on 11 Oct. 2011 and four at Dover on 12 Oct. 2011.

Single-plant plots were spatially organized in randomized complete block designs within each site. The sites were prepared and maintained according to standard commercial practices, which are more fully described in MacKenzie et al. (2011). Briefly, beds were $91.5 \mathrm{~m}$ long, $71 \mathrm{~cm}$ wide, $15 \mathrm{~cm}$ high at the edges, and $18 \mathrm{~cm}$ high in the center and were fumigated with a mixture of telone and chloropicrin approximately one month before transplanting. There were two offset rows of plants per bed. Plant spacing was $38 \mathrm{~cm}$ within rows and $28 \mathrm{~cm}$ between rows. After transplanting, the runner plants were overhead irrigated for $10 \mathrm{~d}$ during daylight hours to facilitate establishment. Once established, the plants were irrigated and fertilized each day exclusively through the drip tape. Field preparation was essentially the same across locations and seasons, but practices such as pest control and fertilization differed across locations and seasons.

SSC was measured four times during the 2010-11 season and five times during the 2011-12 season. Measurements at Dover were taken the day after measurements were taken at Balm (Table 1). One ripe fruit (100\% red) from each plant was squeezed by hand until the expressed juice covered the prism of a handheld digital refractometer (PAL-1; Atago, Tokyo, Japan)

Table 1. Summary statistics for harvest means: percent soluble solids content (SSC) from fruit of strawberry genotypes harvested nine times over two seasons in Balm, FL, and Dover, FL.

\begin{tabular}{|c|c|c|c|c|c|c|c|c|}
\hline \multirow[b]{2}{*}{ Harvest } & \multicolumn{4}{|c|}{ Balm } & \multicolumn{4}{|c|}{ Dover } \\
\hline & Date & Genotypes (no.) & Mean SSC (\%) & $\mathrm{SE}$ & Date & Genotypes (no.) & Mean SSC (\%) & $\mathrm{SE}$ \\
\hline & \multicolumn{8}{|c|}{ 2010-11 Season } \\
\hline 1 & 11 Jan. 2011 & 101 & 9.9 & 0.16 & 12 Jan. 2011 & 84 & 9.8 & 0.20 \\
\hline 3 & 22 Feb. 2011 & 111 & 7.3 & 0.11 & 23 Feb. 2011 & 110 & 6.3 & 0.11 \\
\hline 4 & 8 Mar. 2011 & 109 & 6.0 & 0.08 & 9 Mar. 2011 & 113 & 5.1 & 0.07 \\
\hline 1 & 13 Dec. 2011 & 48 & 9.0 & 0.18 & 14 Dec. 2011 & 51 & 8.4 & 0.13 \\
\hline 2 & 3 Jan. 2012 & 49 & 8.2 & 0.17 & 4 Jan. 2012 & 50 & 8.0 & 0.15 \\
\hline 3 & 24 Jan. 2012 & 47 & 10.6 & 0.21 & 25 Jan. 2012 & 51 & 10.2 & 0.19 \\
\hline 4 & 15 Feb. 2012 & 52 & 8.3 & 0.15 & 14 Feb. 2012 & 47 & 6.9 & 0.16 \\
\hline 5 & 6 Mar. 2012 & 52 & 6.7 & 0.12 & 7 Mar. 2012 & 52 & 6.5 & 0.10 \\
\hline
\end{tabular}


that was calibrated with deionized water. Ripe fruit were not present on all plants on all harvest dates as a result of different ripening patterns. For the first season, only genotypes that were sampled in at least six of eight harvests (four in Balm and four in Dover) were included in the analysis, leaving 329 genotypes in the first set and 113 genotypes in the second set. For the next season, only genotypes sampled in at least eight of 10 harvests (five in Balm and five in Dover) were included in the analysis, reducing the number of genotypes to 173 . The number of genotypes replicated across seasons decreased to 40 .

Constraints in time and labor dictated that SSC could be measured only four or five times within a season for all genotypes in the study. To gain a more detailed picture of the fluctuation of SSC across harvests, a small study was planted adjacent to the main study in Balm in 2011-12. A subset of eight genotypes was clonally replicated 10 times and planted within 10 blocks in a single row. SSC was measured each week for a total of 16 weeks according to the methods previously described.

Stability analysis. SSC stability was estimated for all genotypes using the approach described by Finlay and Wilkinson (1963) in which genotype values are regressed on environmental means. However, rather than estimating stability across environments (unique combinations of location and year), we evaluated the stability of repeated measures across harvests within each environment; therefore, our model permits correlation across observations from the same plant.

As suggested by Freeman and Perkins (1971), independent groups of genotypes were used to estimate a mean for each harvest. The 113 seedling genotypes from the second set of crosses in 2010-11 and 52 randomly chosen advanced selections in 201112 were used exclusively to calculate harvest means (Table 1). These means reflect the combined effects of physiological and environmental conditions that were common to all genotypes and provide estimates of how favorable conditions were for SSC during the relevant interval before harvest. Harvests with low SSC means correspond to periods with unfavorable conditions compared with harvests with higher means.

Only those genotypes that were not used to estimate harvest means were evaluated for stability (Table 2). A linear regression of SSC for each genotype was fitted against harvest means within each environment, and the magnitude of the slope of each genotype was considered an estimate of its stability. The number of slopes estimated per individual varied according to the number of environments in which it was evaluated (up to four).

To detect within-season associations between SSC and yield, individual values of SSC were regressed on each plant's yield at the corresponding harvest date. Only observations from the first three harvest dates of the 2011-12 season were included in this analysis because yield was not recorded at every harvest. More details on data collection are available in Whitaker et al. (2012).

Statistical analysis. Within each season, the SSC of the $r$ th replicate of the $i$ th genotype measured during the $l$ th harvest date at the $m$ th location is given by $y_{i l m r}$, where

$$
\begin{aligned}
y_{i l m r}= & \left(\alpha_{11}+\sum_{i}^{D-1} \beta_{i} d_{i}+\sum_{j}^{S-1} \gamma_{m} s_{m}+\sum_{i}^{D-1} \sum_{j}^{S-1} \theta_{i m} d_{i} s_{m}\right) \\
& +\left(\lambda_{11}+\sum_{i}^{D-1} \rho_{i} d_{i}+\sum_{j}^{S-1} \varsigma_{m} s_{m}\right. \\
& \left.+\sum_{i}^{D-1} \sum_{j}^{S-1} \varphi_{i m} d_{i} s_{m}\right) x_{l(m)}+e_{i l m r}
\end{aligned}
$$

Here, $\alpha_{11}$ is the intercept of genotype 1 at Site 1 (baseline levels of each factor) and $\lambda_{11}$ is the slope of genotype 1 at Site 1 (baseline levels of each factor). The $d_{i} \mathrm{~s}$ are $D-1$ indicator variables for each genotype different from the baseline ( $i=$ $1, \ldots, D)$. If $i^{*}$ represents the genotype under consideration, then

$$
d_{i}=\left\{\begin{array}{l}
1 \text { if } i=i^{*} \\
0 \text { otherwise }
\end{array}\right.
$$

The $s_{m} \mathrm{~s}$ are $S-1$ indicator variables for each site different from the baseline $(m=1, \ldots, S)$. If $m^{*}$ represents the site under consideration, then

$$
s_{m}=\left\{\begin{array}{l}
1 \text { if } m=m^{*} \\
0 \text { otherwise }
\end{array}\right.
$$

The $\beta_{i} \mathrm{~s}, \gamma_{m} \mathrm{~s}$, and $\theta_{i m} \mathrm{~s}$ are fixed effects of genotypes, sites,

\begin{tabular}{|c|c|c|c|c|c|c|c|c|}
\hline \multirow[b]{3}{*}{ Harvest } & \multicolumn{4}{|c|}{ Balm } & \multicolumn{4}{|c|}{ Dover } \\
\hline & \multirow[b]{2}{*}{ Genotypes (no.) } & Mean SSC & Minimum SSC & Maximum SSC & \multirow[b]{2}{*}{ Genotypes (no.) } & \multirow{2}{*}{\multicolumn{3}{|c|}{$\begin{array}{l}\text { Mean SSC } \text { Minimum SSC } \text { Maximum SSC } \\
\end{array}$}} \\
\hline & & \multicolumn{3}{|c|}{ 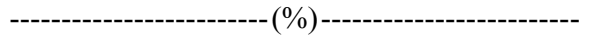 } & & & & \\
\hline & \multicolumn{8}{|c|}{$2010-11$ season } \\
\hline 2 & 272 & 6.5 & 3.3 & 11.4 & 273 & 5.9 & 2.7 & 12.8 \\
\hline 3 & 309 & 7.0 & 4.1 & 12.6 & 314 & 6.5 & 2.8 & 13.7 \\
\hline & \multicolumn{8}{|c|}{ 2011-12 season } \\
\hline 1 & 118 & 9.2 & 4.7 & 13.9 & 118 & 8.3 & 5.6 & 12.0 \\
\hline 2 & 114 & 8.5 & 5.7 & 11.8 & 112 & 8.2 & 5.3 & 12.4 \\
\hline 3 & 116 & 10.7 & 6.7 & 15.5 & 116 & 10.1 & 7.2 & 14.5 \\
\hline 4 & 120 & 8.3 & 4.9 & 12.7 & 113 & 6.7 & 4.3 & 10.4 \\
\hline 5 & 120 & 7.0 & 4.8 & 10.3 & 120 & 6.5 & 4.5 & 9.8 \\
\hline
\end{tabular}
and their interactions, respectively, that allow for complete heterogeneity of intercepts. The combination of terms inside

Table 2. Summary statistics for genotype means: percent soluble solids content (SSC) from fruit of strawberry genotypes harvested nine times over two seasons in Balm, FL, and Dover, FL. ${ }^{\mathrm{z}}$

${ }^{\mathrm{z}}$ Genotypes used to estimate harvest means are not included. 
the first parenthesis represents the general intercept of the model. The $\rho_{i} \mathrm{~s}, \boldsymbol{s}_{m} \mathrm{~s}$, and $\varphi_{i m} \mathrm{~s}$ are fixed effects of genotypes, sites, and their interactions, respectively, that allow for complete heterogeneity of slopes. These terms capture the portion of the variation that is a linear function of the harvest mean value (Perkins and Jinks, 1968). The combination of terms inside the second parenthesis represents the general slope of the model. $X_{l(m)}$ is the SSC mean of harvest $l$ within site $m$ (this is the only quantitative regressor in the model). The term $e_{i l m r} \sim N(0, \Sigma)$ is the residual deviation associated with the $r$ th replicate of the $i$ th genotype in the $m$ th site measured at the lth harvest. This is the only random component in the model, and its variance-covariance matrix, $\Sigma$, was specified as, blockdiagonal with first-order autoregressive structure $\rho_{m}^{\mid k-k^{\prime}} \mid \sigma_{m}^{2}$ on each block. The significance of this structure was tested against the diagonal matrix $\sigma^{2} \mathbf{I}_{n}$ of the ordinary least squares model by means of a likelihood ratio (LR) test. The autocorrelation coefficient $\left(\rho_{m}\right)$ and variance $\left(\sigma_{m}^{2}\right)$ were specific to each location. This structure imposes independence across plants but allows correlation across harvests of individual plants.

Because different populations were evaluated across seasons with a reduced number of genotypes replicated across seasons, independent models for each season were estimated. The models were fitted using the maximum likelihood estimation capabilities of the Mixed Procedure of SAS (Version 9.2; SAS Institute, Cary, NC). The heterogeneity of intercepts and slopes across genotypes and locations was tested by estimating the significance of the fixed effects in the corresponding summations in Eq. [1] by means of $F$ tests. To detect genotypes with slopes that deviate significantly from the population's value, $95 \%$ confidence intervals for the slope of each genotype were calculated. Values of SSC were log-transformed to stabilize the variances.

The regression fitted to evaluate within-season associations between SSC and yield allowed for heterogeneity of slopes across stability groups (stable, average, and unstable) and used the same variance-covariance structure of the model in Eq. [1].

Heritability estimation. Broad-sense $\left(H^{2}\right)$ and narrowsense $\left(h^{2}\right)$ heritabilities of regression slopes were estimated for the first set of seedling genotypes (originating from the factorial mating design), including the second season observations from the replicated trial of advanced selections. The variance components involved in the estimation of $H^{2}$ and $h^{2}$ were generated through univariate analysis using ASReml software (Gilmour et al., 2009). The analysis incorporated pedigree information and was carried out assuming heterogeneous errors across seasons following the general mixed model:

$y_{i j k m n}=\mu+S_{n}+L_{m(n)}+f_{j}+m_{k}+f m_{j k}+g(f m)_{i(m n)}+e_{i j k m n}$

where $y_{i j k m n}$ is the regression slope of the $i^{\text {th }}$ genotype from the $j k^{\text {th }}$ family at the $m^{\text {th }}$ location during the $n^{\text {th }}$ season, $\mu$ is the population mean, $S_{n}$ is the fixed effect of season, $L_{m(n)}$ is the fixed effect of location within season, $f_{j}$ is the female random effect $\sim \operatorname{NIID}\left(0, \sigma_{f}^{2}\right), m_{k}$ is the male random effect $\sim \operatorname{NIID}\left(0, \sigma_{m}^{2}\right), f m_{j k}$ is the family random effect $\sim \operatorname{NIID}\left(0, \sigma_{f m}^{2}\right)$, $g(f m)_{i(j k)}$ is the genotype within family random effect $\sim \mathrm{NIID}\left(0, \sigma_{g}^{2}\right)$, and $e_{i j k m n}$ is the random residual effect associated with each season $\sim \operatorname{NIID}\left(0, \sigma_{e}^{2}\right)$. Wald $\mathrm{F}$ statistics using an incremental $P$ value were used to test the fixed effects (Gilmour et al., 2009).
Estimates of $h^{2}$ and $H^{2}$ were calculated according to the following formulas:

$$
\begin{aligned}
& h^{2}=\frac{2\left(\sigma_{f}^{2}+\sigma_{m}^{2}\right)}{\sigma_{f}^{2}+\sigma_{m}^{2}+\sigma_{f m}^{2}+\sigma_{g}^{2}+\frac{\sum_{n=1}^{2} \sigma_{e}^{2}}{2}} \\
& H^{2}=\frac{\sigma_{f}^{2}+\sigma_{m}^{2}+\sigma_{f m}^{2}+\sigma_{g}^{2}}{\sigma_{f}^{2}+\sigma_{m}^{2}+\sigma_{f m}^{2}+\sigma_{g}^{2}+\frac{\sum_{n=1}^{2} \sigma_{e}^{2}}{2}}
\end{aligned}
$$

\section{Results and Discussion}

Considerable variation of SSC was observed throughout both seasons. Harvest means ranged from $5.1 \%$ to $9.9 \%$ and from $6.5 \%$ to $10.6 \%$ during the first and second seasons, respectively (Table 1). The highest SSC values were consistently observed in January and the lowest values in March, near the conclusion of the typical fruiting season in Florida. This drop in SSC in March is consistent with other studies conducted using commercial cultivars (MacKenzie et al., 2011). The behavior of SSC in Balm during the 2011-12 season for five harvests is illustrated in Figure 1 in comparison with a small adjacent study, which was harvested 16 times throughout the season. The five sampled harvest dates seem to be representative of the seasonal variation as a whole, because they include both extreme and midrange values.

The SSC of the evaluated genotypes varied quite dramatically (Table 2). The range of genotype means during the first season was slightly wider $(2.7 \%$ to $17.9 \%)$ than the range observed during the second season $(4.3 \%$ to $15.5 \%)$. Factors such as the different number of genotypes in each season, the fact that genotypes in the second season had undergone

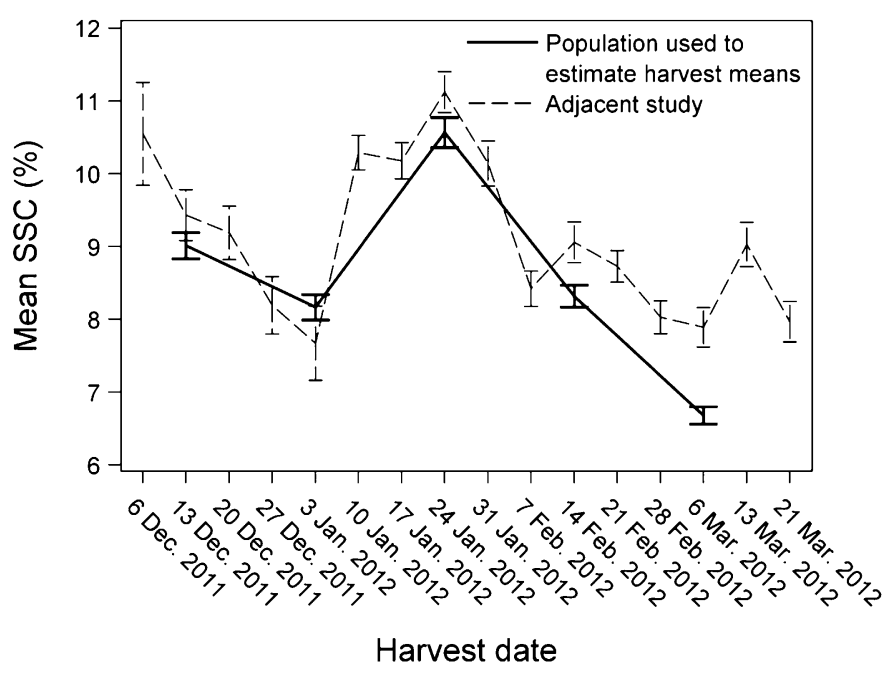

Fig. 1. Within-season behavior of the soluble solids content (SSC) for an independent set of 52 randomly chosen strawberry seedlings and selections used to estimate harvest means for the main population under study compared with the values from an adjacent but independent trial with a subset of eight strawberry genotypes harvested each week (2011-12 season in Balm, FL). Bars represent SE. 
selection for a suite of commercial traits including flavor, and different weather conditions across seasons could all have a role in the reduced variability in 2011-12.

Results for the fixed effects from Eq. [1] are presented in Table 3. The heterogeneity of slopes across genotypes (harvest $\times$ genotype interaction) was highly significant in both seasons. This confirms that genotypes differ in their response to harvest dates and, therefore, have significantly different stabilities as defined by Finlay and Wilkinson (1963). This also lends additional support to the results of Jouquand et al. (2008) and Whitaker et al. (2011) who observed that the SSC of some genotypes is more variable than others. The significant three-way interaction (harvest $\times$ genotype $\times$ location) revealed slope inconsistency across locations. In other words, one or more strawberry genotypes differed in their response to harvest date in Balm compared with Dover.

The fitting of the models was significantly improved by using the autoregressive covariance structure as an alternative to using the diagonal matrix structure of the ordinary least squares estimation [LR $(P<0.001)]$. This implies that important information was gained by modeling correlation across repeated measures.

Given that parents of all seedlings shared pedigree linkages and were not explicitly selected for stability, we expected both seedling sets to behave similarly on average throughout the season. Therefore, the slopes of the population regression lines were anticipated to be close to 1.0. Comparable behavior was also expected from both groups of advanced selections resulting from randomization of the groups. The estimated population slopes were 1.18 in Balm and 1.03 in Dover during 2010-11 and were 0.94 in Balm and 1.03 in Dover during 2011-12. Only the first slope of 1.18 deviated significantly from the expected value of 1.0. As mentioned by Freeman and Perkins (1971), populations may diverge from unity when an independent group of genotypes is used to estimate harvest means. Nevertheless, genotypes with steeper slopes will still be associated with lower stability, and genotypes with flatter slopes will still be associated with higher stability.

Approximately $95 \%$ of genotype slopes ranged between 0 and 2.5 across the four environments. Estimates outside this

Table 3. Multiple regression results: Type III tests of fixed effects of genotype, location, and harvest on soluble solids content (SSC) of strawberry fruit harvested from seedlings and breeding selections in two locations (Balm, FL, and Dover, FL) over two seasons.

\begin{tabular}{|c|c|c|c|c|c|c|}
\hline \multirow{2}{*}{$\begin{array}{l}\text { Source of } \\
\text { variation }\end{array}$} & \multicolumn{3}{|c|}{ 2010-11 season ${ }^{z}$} & \multicolumn{3}{|c|}{$2011-12$ season $^{y}$} \\
\hline & $\mathrm{df}_{\text {num }}{ }^{\mathrm{x}}$ & $\mathrm{df}_{\mathrm{den}}^{\mathrm{x}}$ & $P$ value & $\overline{d f_{\text {num }}}$ & $\mathrm{df}_{\mathrm{den}}$ & $P$ value \\
\hline Genotype (G) & 328 & 627 & $<0.001$ & 120 & 551 & $<0.001$ \\
\hline Location (L) & 1 & 627 & $<0.001$ & 1 & 551 & 0.025 \\
\hline $\mathrm{G} \times \mathrm{L}$ & 328 & 627 & $<0.001$ & 120 & 551 & 0.057 \\
\hline Harvest (H) & 1 & 1958 & $<0.001$ & 1 & 1966 & 0.001 \\
\hline $\mathrm{H} \times \mathrm{G}$ & 328 & 1958 & $<0.001$ & 120 & 1966 & $<0.001$ \\
\hline $\mathrm{H} \times \mathrm{L}$ & 1 & 1958 & $<0.001$ & 1 & 1966 & 0.056 \\
\hline $\mathrm{H} \times \mathrm{G} \times \mathrm{L}$ & 328 & 1958 & $<0.001$ & 120 & 1966 & 0.044 \\
\hline
\end{tabular}

${ }^{\mathrm{z}}$ For 2010-11: $\sigma_{\text {Balm }}^{2}=0.02723 ; \sigma_{\text {Dover }}^{2}=0.03592 ; \rho^{2}{ }_{\text {Balm }}=-0.2154$ and $\rho_{\text {Dover }}^{2}=-0.2493$.

${ }^{\mathrm{y}}$ For 2011-12: $\sigma^{2}{ }_{\text {Balm }}=0.03139 ; \sigma^{2}$ Dover $=0.02807 ; \rho^{2}{ }_{\text {Balm }}=-0.1399$ and $\rho^{2}$ Dover $=-0.1431$.

${ }^{x} \mathrm{df}_{\text {num }}$ and $\mathrm{df}_{\text {den }}$ indicate the number of $\mathrm{df}$ for the numerator and denominator used to derive $\mathrm{F}$ statistics. range are reported, but such extreme values should be regarded with caution. In each environment, genotypes were classified as stable, unstable, or as having average stability if their slopes were significantly less, greater, or not different from their corresponding population slope value. Figure 2 shows the regression lines of three genotypes representing each group. Harvest dates with unfavorable conditions are located on the left portion of the horizontal axis with higher means toward the right. Selection FL 10-168 is representative of individuals with average stability. Its line runs parallel to the population line, because it maintained close to average levels of SSC throughout the season. In contrast, selection FL 10-169 was classified as unstable because small changes in field conditions produced large changes in SSC. It had relatively low SSC under poor conditions but eventually exceeded the population average under better conditions. Finally, FL 10-177 represents stable individuals. It had average SSC under favorable conditions but above-average SSC under unfavorable conditions.

It is possible to describe the overall SSC behavior of a single genotype by its mean across all harvest dates and the slope of its regression line. Figure 3 shows the distribution of these two variables for each environment. The majority of individual slopes $(\approx 90 \%)$ did not significantly deviate from their corresponding population slopes and were therefore part of the average stability group. The remaining $10 \%$ were equally distributed between the unstable and stable groups. Unstable, average and stable genotypes are respectively clustered in the upper, middle, and lower portion of each panel in Figure 3 . Notably, each group is distributed across the values of SSC on the horizontal axis, suggesting that stability (static or dynamic) is not associated with specific levels of mean SSC. This hypothesis is supported by a low Pearson correlation coefficient $(r=0.018)$ that was not significantly different from zero $(\alpha=0.05)$. The independence of these two traits means that it is possible to observe individuals with both stable and high levels of soluble solids. This was not necessarily expected, because stability analyses in other crops and traits have frequently associated high stability with low overall means (Goyal et al., 2011).

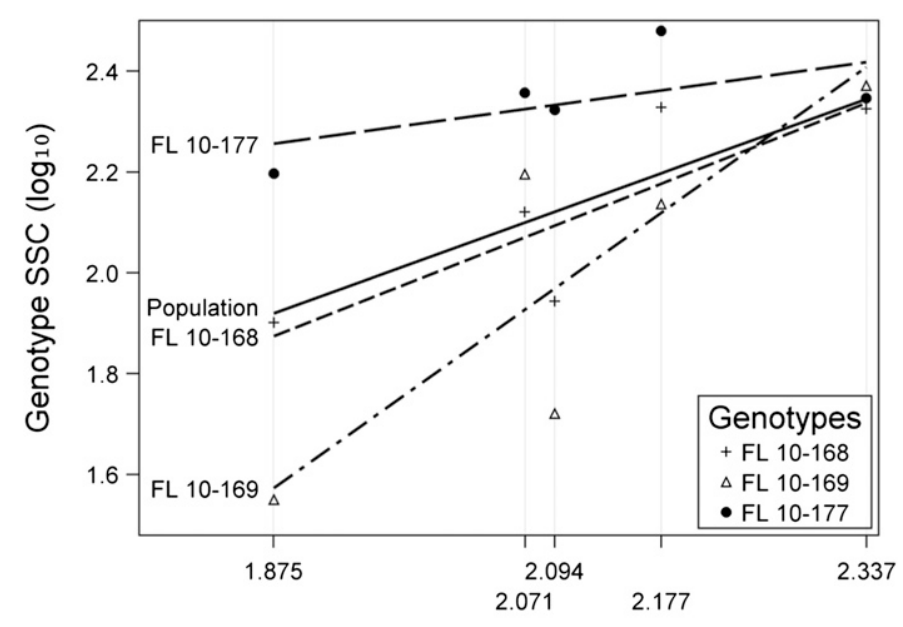

Harvest date mean SSC $\left(\log _{10}\right)$

Fig. 2. Regression lines of soluble solids content (SSC) on harvest date means for three strawberry genotypes illustrating heterogeneity of slopes. The population line was included for reference (2011-12 season in Balm, FL). 


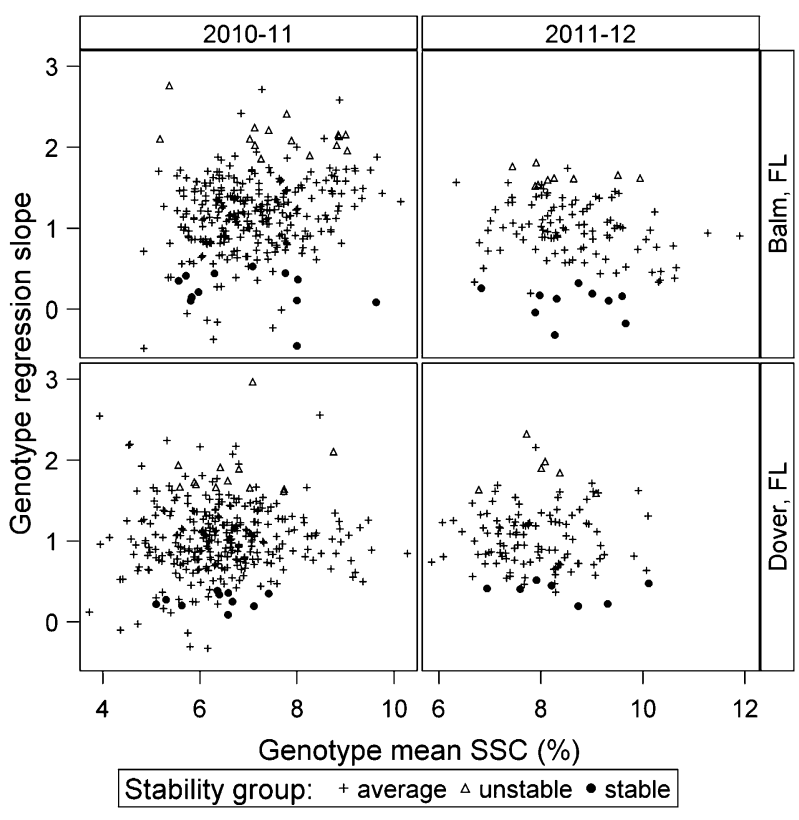

Fig. 3. Distribution of regression slope and overall means of soluble solids content (SSC) for individual strawberry genotypes by season and location. Symbols show the regression slope for each individual as being significantly lower (stable), significantly higher (unstable), or not significantly different (average) from the respective population slope value.

Whitaker et al. (2012) estimated genetic correlations between mean SSC and other plant and fruit traits using some of the same breeding populations as in the present study. For most pairs of traits (such as for SSC and fruit size), correlations were low in magnitude, had high SES, or both. However, for SSC and marketable yield, an additive genetic correlation $( \pm \mathrm{SE})$ of $-0.76 \pm 0.15$ indicated that selection for higher SSC in the University of Florida strawberry breeding program could reduce genetic gains for yield over time and vice versa. This raises the question of whether there is also a negative relationship between SSC stability and fruit yield. Such a relationship is not apparent at the phenotypic level, because Pearson correlation coefficients between SSC regression slopes and means of early yield $(r=0.011)$ and total yield $(r=0.015)$ were not statistically different from zero $(\alpha=0.05)$. However, yield on individual plants fluctuates over the course of the season, and it is possible that negative correlations could exist between yield and SSC at individual harvest dates, thereby influencing SSC stability. As a result of labor and time constraints, fruit were only weighed on three of the harvest dates on which SSC was measured. Nevertheless, to examine this question, individual values of SSC were regressed on each plant's yield at the corresponding harvest date. The regression did not detect linear relationships in the population as a whole or within each stability group, suggesting that changes in fruit load did not significantly affect SSC throughout the season. However, because the model only considers yield recorded on the date SSC was measured, and does not consider fruit harvested before and after each SSC evaluation, the fruit load during the development of the evaluated fruit is underestimated. For this reason it is not possible, using the data at hand, to rule out the contribution of genotype-specific fruiting patterns to within-season SSC stability.

Within each season, most genotypes (81\%) were consistently classified in the same stability group across locations.
The remaining genotypes switched groups as predicted by the significant three-way interaction reported in Table 3. However, only one genotype switched between the stable and unstable groups. The remaining genotypes switched from stable to average or unstable to average and vice versa. It is possible that certain factors differed across locations and affected the stability of some genotypes more than others. Unfortunately, because this approach uses an overall measure of all the conditions affecting each harvest, it is not possible to isolate the effect of individual factors. Some discrepancies across locations and seasons may also arise as a result of the chosen statistical methods. Because the null hypothesis places all genotypes in the average group unless there is enough evidence to conclude otherwise, some disagreements may be a consequence of high levels of Type II error.

Table 4 lists the group of genotypes that were replicated across seasons. Only 40 of the 50 genotypes had sufficient observations to estimate their slopes in both seasons. As discussed previously, there are discrepancies in slope across the four environments. However, genotypes FL 10-144, FL 10153, FL 10-155, and FL 10-177 were classified as stable in one environment and exhibited values smaller than the population averages in two other environments. FL 10-175 was notable in that it was classified as stable in one environment and also had slope values smaller than the population in the three other environments. Similarly, FL 10-151 was classified as unstable in one environment and had slope values larger than the population in the other three environments. FL 10-169 was the only genotype that switched from stable in 2010-11 to unstable in 2011-12.

The estimate of narrow sense heritability for the slope was low $\left(h^{2}=0.06 \pm 0.05\right)$, and no dominance effects were detected. This indicates that there may be a small amount of genetic control for stability. Low heritability implies that environmental (non-genetic) conditions were responsible for most of the variation in SSC stability observed in the population. For comparison, estimates of heritability for SSC mean from a previous study were $H^{2}=0.30 \pm 0.04$ and $h^{2}=0.21 \pm 0.08$ (Whitaker et al., 2012). Because stability was estimated as a function of harvest means (an environmental index), low genetic control was expected for this trait. Although higher heritabilities would be desirable from a breeding standpoint, it is nonetheless encouraging that a group of genotypes consistently obtained small slopes under multiple environments. This is noteworthy for an estimated trait that has a substantial amount of inherent error variation. It is possible that improvements in sampling could reduce error variation and lead to higher heritability estimates that would facilitate gains from selection. It is also possible that multiple generations of selection for stability could affect the heritability of the trait. In the present study, stable individuals contribute a small amount of variation, only representing $5 \%$ of the individuals in the population.

It is important to mention that, for each genotype, only one slope could be estimated per location, making location the unit of replication for slope. The lack of replicated slopes for each location affects the accuracy of genetic parameter estimates and does not allow an estimate of the genotype $\times$ location interaction effect (shown to be significant in the regression analysis). In the future, heritability estimates might be effectively improved by the use of greater numbers of clonal replicates. Greater precision could also be obtained by evaluating SSC at 
Table 4. Stability (regression slope) of soluble solids content (SSC) of 40 strawberry genotypes evaluated at two Florida locations during each of two seasons. ${ }^{\mathrm{z}}$

\begin{tabular}{|c|c|c|c|c|c|c|c|c|}
\hline \multirow[b]{2}{*}{ Genotype } & \multicolumn{4}{|c|}{$2010-11^{\mathrm{y}}$} & \multicolumn{4}{|c|}{$2011-12^{\mathrm{y}}$} \\
\hline & Balm & & Dove & & Baln & & Dove & \\
\hline FL 10-130 & 1.07 & & 1.26 & & 0.89 & & 1.34 & \\
\hline FL 10-131 & 1.27 & & 1.46 & & 1.29 & & 1.09 & \\
\hline FL $10-134$ & 1.13 & & 1.73 & & 1.52 & + & 0.81 & \\
\hline FL $10-135$ & 1.11 & & 1.47 & & 0.94 & & 0.63 & * \\
\hline FL 10-137 & 1.62 & & 1.43 & & 1.54 & & 2.16 & \\
\hline FL $10-138$ & 1.19 & & 1.38 & & 0.88 & & 1.32 & \\
\hline FL 10-139 & 0.61 & & 1.01 & & 0.61 & & 0.81 & \\
\hline FL $10-140$ & 1.13 & & 0.20 & $*$ & 1.24 & & 1.18 & \\
\hline FL 10-141 & 1.47 & & 1.15 & & 1.01 & & 1.16 & \\
\hline FL $10-143$ & 1.27 & & 1.37 & & 0.89 & & 0.72 & \\
\hline FL 10-144 & 0.41 & $*$ & 0.82 & & 1.09 & & 0.94 & \\
\hline FL $10-145$ & 1.21 & & 2.55 & & 1.60 & + & 0.72 & \\
\hline FL $10-147$ & 1.46 & & 1.31 & & 0.97 & & 0.78 & \\
\hline FL $10-151$ & 1.35 & & 1.70 & + & 1.22 & & 1.45 & \\
\hline FL $10-153$ & -0.06 & & 0.39 & $*$ & 0.93 & & 1.25 & \\
\hline FL $10-154$ & 1.47 & & 1.37 & & 1.23 & & 0.95 & \\
\hline FL 10-155 & 0.89 & & 0.90 & & 0.26 & $*$ & 1.11 & \\
\hline FL $10-156$ & 1.55 & & 0.77 & & 1.38 & & 0.65 & * \\
\hline FL 10-157 & 0.76 & & 0.67 & & 1.02 & & 1.32 & \\
\hline FL 10-159 & 0.82 & & 0.90 & & 1.56 & & 0.76 & \\
\hline FL $10-162$ & 0.65 & & 0.99 & & 0.74 & & 1.20 & \\
\hline FL $10-163$ & 1.17 & & 0.81 & & 0.68 & & 1.24 & \\
\hline FL $10-164$ & 1.13 & & 0.65 & & 1.27 & & 1.08 & \\
\hline FL 10-166 & 0.97 & & 1.06 & & 1.06 & & 1.49 & \\
\hline FL $10-167$ & 0.84 & & 1.74 & + & 0.76 & & 0.84 & \\
\hline FL $10-168$ & 0.61 & & 1.54 & & 1.00 & & 1.09 & \\
\hline FL $10-169$ & 0.21 & $*$ & 1.62 & & 1.81 & + & 1.47 & \\
\hline FL $10-170$ & 1.11 & & 1.19 & & 1.11 & & 0.55 & * \\
\hline FL $10-171$ & 0.53 & $*$ & 1.24 & & 0.88 & & 1.31 & \\
\hline FL $10-172$ & 1.18 & & 1.11 & & 1.35 & & 0.54 & * \\
\hline FL $10-175$ & 0.80 & & 0.79 & & 0.74 & & 0.22 & * \\
\hline FL $10-177$ & 2.42 & & 0.65 & & 0.38 & $*$ & 0.61 & \\
\hline FL 10-179 & 1.74 & & 1.27 & & 0.36 & $*$ & 1.06 & \\
\hline FL $10-180$ & 0.97 & & 0.86 & & 0.72 & & 1.00 & \\
\hline FL 10-181 & 1.29 & & 1.02 & & 1.20 & & 1.19 & \\
\hline FL $10-184$ & 0.56 & & 0.83 & & 0.74 & & 1.19 & \\
\hline FL 10-185 & 0.69 & & 0.91 & & 1.39 & & 1.27 & \\
\hline FL $10-187$ & 1.34 & & 0.91 & & 1.15 & & 1.23 & \\
\hline 'Florida Radiance' & 0.80 & & 1.36 & & 1.57 & & 1.09 & \\
\hline Winterstar ${ }^{\mathrm{TM}}$ & 2.02 & + & 0.76 & & 0.69 & & 0.78 & \\
\hline Population & 1.18 & & 1.03 & & 0.94 & & 1.03 & \\
\hline
\end{tabular}

${ }^{\mathrm{z}}$ Slopes smaller than their corresponding population values are indicated in bold.

y*Significantly smaller than its corresponding population value $(\alpha=$ $0.05)$; +significantly higher than its corresponding population value $(\alpha=0.05)$.

more harvest dates or measuring subsamples (multiple fruit per plant) at each harvest date.

\section{Conclusions}

Results from this study revealed that the within-season stability of SSC, as measured in this study, is a trait that shows statistically significant variation across genotypes in the strawberry breeding program at the University of Florida. Although the heritability of SSC stability appears to be low, this study has identified genotypes having within-season SSC stability under multiple environments. The data suggest that stability is not phenotypically associated with specific levels of SSC or yield, and individuals with both stable and high levels of SSC were identified in the population.

It could be argued that average stability (a slope near the population slope value) is desirable because it would ensure high performance for SSC during favorable environmental conditions. However, the critical challenge for strawberry growers in Florida is not to incrementally improve SSC early in the season when market supply is low and fruit quality is generally acceptable but to maintain quality at the conclusion of the season when overall market supply increases and conditions are unfavorable for SSC. Under this circumstance, stability in the static sense (regression slopes nearer zero) is the most advantageous.

In the future, it would be advisable to more comprehensively examine the influence of genotype-specific yield fluctuations on SSC stability as well as the impact of environmental variables like temperature and precipitation. Such information may help to refine practical strategies for improving within-season stability of SSC in strawberries.

\section{Literature Cited}

Ashburner, G.R., B.M. Top, A.P.L. Callinan, S.J. Wade, M.J. Hickey, and W.J. Ashcroft. 2003. Relationship between environmental stability of cultivars and their adoption in the Australian processing tomato industry. Acta Hort. 613:305-310.

Becker, H. and J. Leon. 1988. Stability analysis in plant breeding. Plant Breed. 101:1-23.

Finlay, K. and G. Wilkinson. 1963. The analysis of adaptation in a plant breeding programme. Aust. J. Agr. Res. 14:742-754.

Forney, C.F. and P.J. Breen. 1985. Growth of strawberry fruit and sugar uptake of fruit discs at different inflorescence positions. Sci. Hort. 27:55-62.

Freeman, G. 1973. Statistical methods for the analysis of genotypeenvironment interactions. Heredity 31:339-354.

Freeman, G. and J. Perkins. 1971. Environmental and genotypeenvironmental components of variability. VIII. Relations between genotypes grown in different environments and measures of these environments. Heredity 27:15-23.

Gilmour, A.R., B.J. Gogel, B.R. Cullis, and R. Thompson. 2009. ASReml user guide release 3.0. 15 Nov. 2011. <http://www.vsni.co.uk>.

Goyal, A., B.L. Beres, H.S. Randhawa, A. Navabi, D.F. Salmon, and F. Eudes. 2011. Yield stability analysis of broadly adaptive triticale germplasm in southern and central Alberta, Canada, for industrial end-use suitability. Can. J. Plant Sci. 91:125-135.

Gupton, C., J. Clark, D. Creech, A. Powell, and S. Rooks. 1996. Comparing stability indices for ripening date and yield in blueberry. J. Amer. Soc. Hort. Sci. 121:204-209.

Jouquand, C., A. Plotto, K. Goodner, and C.K. Chandler. 2008. A sensory and chemical analysis of fresh strawberries over harvest dates and seasons reveals factors that affect eating quality. J. Amer. Soc. Hort. Sci. 133:859-867.

Lee, J., K.D. Bilyeu, V.R. Pantalone, A.M. Gillen, Y. So, and J.G. Shannon. 2012. Environmental stability of oleic acid concentration in seed oil for soybean lines with FAD2-1A and FAD2-1B mutant genes. Crop Sci. 52:1290-1297.

MacKenzie, S.J. and C.K. Chandler. 2009. A method to predict weekly strawberry fruit yields from extended season production systems. Agron. J. 101:278-287.

MacKenzie, S.J., C.K. Chandler, T. Hasing, and V.M. Whitaker. 2011. The role of temperature in the late-season decline in soluble solids content of strawberry fruit in a subtropical production system. HortScience 46:1562-1566. 
Maupin, L., M.L. Rosso, C. Shang, and K.M. Rainey. 2011. Genotype by environment interaction and stability of phosphorus concentration in two soybean germplasm sources with modified phosphorus composition. Crop Sci. 51:1518-1524.

Murphy, S.E., E.A. Lee, L. Woodrow, P. Seguin, J. Kumar, I. Rajcan, and G.R. Ablett. 2009. Genotype by environment interaction and stability for isoflavone content in soybean. Crop Sci. 49:1313-1321.

Olsen, J.L., L.W. Martin, P.J. Pelofske, P.J. Breen, and C.F. Forney. 1985. Functional growth analysis of field grown strawberry. J. Amer. Soc. Hort. Sci. 110:89-93.

Perkins, J.M. and J.L. Jinks. 1968. Environmental and genotypeenvironmental components of variability. III. Multiple lines and crosses. Heredity 23:339-356.

Perkins-Veazie, P. 1995. Growth and ripening of strawberry fruit. Hort. Rev. 17:267-297.

Shaw, D.V. 1988. Genotypic variation and genotypic correlations for sugars and organic acids of strawberries. J. Amer. Soc. Hort. Sci. 113:770-774.

Shaw, D.V. 1990. Response to selection and associated changes in genetic variance for soluble solids and titratable acids contents in strawberries. J. Amer. Soc. Hort. Sci. 115:839-843.
Shaw, D.V., R. Bringhurst, and V. Voth. 1987. Genetic variation for quality traits in an advanced-cycle breeding population of strawberries. J. Amer. Soc. Hort. Sci. 112:699-702.

Sims, C.A., C.K. Chandler, and T.E. Crocker. 1997. Sensory fruit quality of strawberry cultivars in central Florida. Proc. Florida State Hort. Soc. 110:178-180.

Stoffella, P.J., S.J. Locascio, T.K. Howe, S.M. Olson, K.D. Shuler, and C.S. Vavrina. 1995. Yield and fruit size stability differs among bell pepper cultivars. J. Amer. Soc. Hort. Sci. 120:325-328.

Whitaker, V.M., T. Hasing, C.K. Chandler, A. Plotto, and E. Baldwin. 2011. Historical trends in strawberry fruit quality revealed by a trial of University of Florida cultivars and advanced selections. HortScience 46:553-557.

Whitaker, V.M., L.F. Osorio, T. Hasing, and S. Gezan. 2012. Estimation of genetic parameters for twelve fruit and vegetative traits in the University of Florida strawberry breeding population. J. Amer. Soc. Hort. Sci. 137:316-324.

Wozniak, W., B. Radajewska, A. Reszelska-Sieciechowicz, and I. Dejwor. 1997. Sugars and acid content influence organoleptic evaluation of fruits of six strawberry cultivars from controlled cultivation. Acta Hort. 439:333-336. 